\title{
SUBSTANCE P: IONIC BASIS FOR DEPOLARIZING RESPONSES OF MOUSE SPINAL CORD NEURONS IN CELL CULTURE ${ }^{1}$
}

\author{
LINDA M. NOWAK ${ }^{*, 2}$ AND ROBERT L. MACDONALD $\ddagger^{3}$ \\ ${ }^{*}$ Neurosciences Program and $\ddagger$ Department of Neurology, University of Michigan, Ann Arbor, Michigan 48109
}

Received November 2, 1981; Revised January 25, 1982; Accepted March 19, 1982

\begin{abstract}
Intracellular recording methods were used to investigate the ionic basis for the postsynaptic actions of substance $P(\mathrm{SP})$ on mouse spinal cord neurons grown in primary dissociated cell culture. $\mathrm{SP}$ and an analog, eledoisin-related peptide (ERP), were applied to single neurons by pressure ejection of peptide-containing solutions from blunt (2- to $10-\mu \mathrm{m})$ glass micropipettes. SP and ERP had similar excitatory actions, increasing spontaneous activity and depolarizing neurons by decreasing membrane conductance. Depolarizing responses were not inverted by intracellular injection of chloride ions, suggesting that SP responses did not result from decreased chloride conductance. SP and ERP responses were not abolished by extracellular tetraethylammonium ions $\left(\mathrm{TEA}^{+}\right)$but were reduced or eliminated by intracellular $\mathrm{TEA}^{+}$, suggesting that SP reduced a potassium conductance $\left(g_{K}\right)$. Finally, SP and ERP responses were larger when neurons were depolarized and smaller when the cells were hyperpolarized, and extrapolated reversal potentials for the peptide responses were 10 to $30 \mathrm{mV}$ more negative than resting membrane potential. Thus, it was concluded that SP depolarized spinal cord neurons by decreasing a membrane potassium conductance. However, SP and ERP response polarity was not clearly reversed even at membrane potentials more negative than the expected potassium equilibrium potential. Moreover, extrapolated reversal potentials $\left(R P_{\mathrm{e} s}\right)$ of SP responses varied linearly with the logarithm of extracellular potassium concentration $\left(\left[\mathrm{K}^{+}\right]_{0}\right)$ as predicted by the Nernst equation for potassium in $\left[\mathrm{K}^{+}\right]_{0}$ concentrations of $10,15,20$, and $40 \mathrm{~mm}$ but were more depolarized than predicted for $\left[\mathrm{K}^{+}\right]_{\mathrm{o}}$ concentrations of 1 and $5 \mathrm{~mm}$. Since reduction of extracellular sodium by choline substitution did not alter the deviation from the Nernst equation for potassium, it was concluded that SP decreased a voltage-dependent potassium conductance which was absent at very negative potentials, present at resting membrane potential, and activated by membrane depolarization. Thus, SP decreases a conductance which appears similar to the muscarinesensitive potassium conductance in sympathetic ganglion neurons (Brown, D. A., and P. R. Adams (1980) Nature 283: 673-676).
\end{abstract}

Substance $\mathrm{P}(\mathrm{SP})$ is a putative peptide neurotransmitter (Lembeck, 1953) of primary sensory neurons (Hökfelt et al., 1975; Otsuka et al., 1975; Takahashi and Otsuka, 1975) and is postulated to be particularly important in

\footnotetext{
' This work was submitted in partial fulfillment of the requirements for the degree of Doctor of Philosophy in Neurosciences at the University of Michigan (L. M. N.). L. M. N. was supported by a predoctoral fellowship from The Horace H. Rackham Graduate School. This research was supported in part by National Institutes of Health Research Career Development Award NS 00408 to K. L. M. We want to thank Dr. Eric Heyer for helpful discussions, Mr. Frank Wilk and Mr. Robert Frere for technical assistance, and Ms. Kathy Lundquist for manuscript preparation. This work was presented in part as a short communication (Nowak, L. M., and R. L. Macdonald (1981) Brain Res. 214: 416-423).

${ }^{2}$ Present address: Ecole Normale Superiéure, Paris 5, France.

${ }^{3}$ To whom correspondence should be addressed at Neuroscience Lab Building, University of Michigan, 1103 E. Huron Street, Ann Arbor, MI 48109.
}

the transmission of pain information (Henry, 1976b). Neurons in the dorsal horn of the spinal cord (Henry, 1976a; Randić and Miletić, 1977; Sastry, 1979; Hayes and Tyers, 1980) and in the trigeminal nucleus (Henry et al., 1980 ) that are activated by noxious cutaneous stimuli also are stimulated by application of SP. Moreover, SPlike immunoreactivity is localized within spinal cord laminae I to III (Hökfelt et al., 1975) and the trigeminal nucleus (Hökfelt et al., 1977; Cuello et al., 1978). SP-like immunoreactivity is localized within nerve terminals and/or varicosities (Ljundahl et al., 1978) which make synaptic contact with neurons in the dorsal horn (ChanPalay and Palay, 1977; Barber et al., 1979; Vacca et al., 1980) and near presumptive motor neurons in the ventral horn (Barber et al., 1979; Vacca et al., 1980). The location of cell bodies of SP-containing fibers in the ventral horn is uncertain since dorsal rhizotomy results primarily in depletion of dorsal horn SP (Hökfelt et al., 1975; Taka- 
hashi and Otsuka, 1975; Jessell ct al., 1979). However, SP is not restricted to primary sensory neurons since a small population of intrinsic SP-containing spinal cord neurons has been described (Ljundahl et al., 1978; Barber et al., 1979) and descending SP-containing fibers have been demonstrated using immunocytochemical techniques (Hökfelt et al., 1978).

Two types of depolarizing SP responses have been described: a slow, prolonged depolarization (Konishi and Otsuka, 1974a, b) associated with an increase (Otsuka and Konishi, 1977; Nicoll, 1978; Dun and Karczmar, 1979), a decrease (Krnjević, 1977; Grafe et al., 1979; Katayama and North, 1978; Katayama et al., 1979; Macdonald and Nowak, 1981; Nowak and Macdonald, 1981a; Hösli et al., 1981), or no change (Sastry, 1979; Zieglgänsberger and Tulloch, 1979) of membrane conductance and a rapid, desensitizing depolarization associated with an increase of membrane conductance (Vincent and Barker, 1979). Intracellular recordings from cat dorsal horn and cuneate neurons suggested that SP reduced either chloride or potassium conductance (Krnjević, 1977) and evidence from guinea pig myenteric neurons strongly suggested that SP decreased membrane potassium conductance (Katayama and North, 1978; Katayama et al., 1979).

We have investigated slow, postsynaptic SP responses of mouse spinal cord neurons grown in primary dissociated cell culture and report that SP depolarized some large multipolar spinal cord neurons by reducing a potassium conductance which may be voltage dependent.

\section{Materials and Methods}

Cell culture. Primary dissociated cell cultures were prepared from spinal cords and attached dorsal root ganglia dissected from 12- to 14-day-old mouse embryos as described previously (Ransom et al., 1977). Cells were dissociated mechanically and plated on 35-mm collagencoated plastic dishes in initial growth medium containing: 80\% modified Eagle's minimum essential medium (MEM) with added glucose (to 6\%) and sodium bicarbonate (to $3.7 \%$ ), $10 \%$ fetal calf serum, and $10 \%$ horse serum (HS) heated to $56^{\circ} \mathrm{C}$ for $30 \mathrm{~min}$ to inactivate complement. Cells from one-fourth or one-half spinal cord with attached dorsal root ganglia were plated on individual culture dishes and incubated at $35^{\circ} \mathrm{C}$ in $10 \%$ $\mathrm{CO}_{2}, 90 \%$ air atmosphere. The growth of non-neuronal cell populations was inhibited by the addition of mitotic inhibitors (uridine and 5'-fluoro-2'-deoxyuridine) for 72 to $96 \mathrm{hr}, 2$ to 4 days after plating. Cell cultures were subsequently maintained with 90\% MEM, 10\% HS medium for 4 to 10 weeks prior to electrophysiological experiments.

Intracellular recording. Spinal cord and dorsal root ganglion neurons were penetrated with one or two high impedance (25- to 45-megohm) glass micropipettes on the heated $\left(34\right.$ to $\left.36^{\circ} \mathrm{C}\right)$, modified stage of an inverted phase contrast microscope. Spinal cord neurons were distinguished from dorsal root ganglion neurons by morphological and electrophysiological criteria (Peacock el al., 1973; Godfrey et al., 1975; Ransom et al., 1977; Ransom and Holz, 1977; Heyer and Macdonald, 1982). Recording micropipettes were filled with 4 M potassium acetate (KAc), $3 \mathrm{M}$ potassium chloride $(\mathrm{KCl})$, or $4 \mathrm{M}$ tetraethylammonium chloride (TEA-Cl). Simultaneous recording and current injection during single electrode recordings were permitted by a conventional bridge circuit (single electrode current clamp). During two-electrode recordings, one electrode was used to pass current and the other was used to record potential (two-electrode current clamp). Membrane conductance measurements were made during recording by passing brief (30- to 300 msec) hyperpolarizing constant current pulses through the intracellular micropipette and recording voltage responses with the same or a second micropipette. Data were recorded with a six-channel rectilinear polygraph and signals were filtered on occasion $(-3 \mathrm{~dB}$ at $15 \mathrm{~Hz})$.

Recordings were made in either phosphate-buffered saline (PBS) or Tris-HCl-buffered saline (TBS). The concentrations of cations were varied in many of the experiments. Therefore, in the text, PBS refers to medium containing: $137.0 \mathrm{~mm} \mathrm{NaCl}, 1.0 \mathrm{~mm} \mathrm{CaCl}, 1.0 \mathrm{~mm}$ $\mathrm{MgCl}_{2}, 2.7 \mathrm{~mm} \mathrm{KCl}, 1.5 \mathrm{~mm} \mathrm{KH}_{2} \mathrm{PO}_{4}, 8.0 \mathrm{mM} \mathrm{Na} \mathrm{HPO}_{4}$, and $5.6 \mathrm{~mm}$ dextrose and TBS refers to medium containing: $145 \mathrm{~mm} \mathrm{NaCl}, 1.0 \mathrm{~mm} \mathrm{CaCl}, 0.8 \mathrm{~mm} \mathrm{MgCl}_{2}, 5.0 \mathrm{~mm}$ $\mathrm{KCl}, 13.0 \mathrm{~mm}$ Tris, and $5.6 \mathrm{~mm}$ dextrose unless ion substitutions, deletions, or additions are indicated. When $\mathrm{MgCl}_{2}$ or $\mathrm{CaCl}_{2}$ concentrations were increased or when $\mathrm{MnCl}_{2}$ or $\mathrm{CoCl}_{2}$ was added to TBS to eliminate synaptic activity (Katz and Miledi, 1967; Baker et al., 1973; Adams and Gage, 1979), the $\mathrm{NaCl}$ concentration was adjusted to maintain osmolarity. The $\mathrm{NaCl}$ concentration was adjusted when the potassium channel blocker TEA-Cl (Armstrong, 1969, 1971) and 3-aminopyridine (Yeh et al., 1976) were added to the medium or whenever the $\mathrm{KCl}$ content of the buffers was changed. Choline chloride (140 mM) was substituted for $\mathrm{NaCl}$ when the $\mathrm{Na}^{+}$concentration was reduced to $5 \mathrm{~mm}$ in TBS which contained either 1 or $5 \mathrm{~mm} \mathrm{KCl}$. Tetrodotoxin (TTX), a sodium conductance-blocking agent (Narahashi et al., 1964), was added directly to the buffer ( $3 \mu 1$ of $1 \mathrm{~mm}$ TTX $/ \mathrm{ml}$ buffer) without adjustment. TTX, rather than cobalt or manganese, was added to reduce spontaneous and synaptic activity in a majority of experiments since high concentrations of divalent cations reduce SP binding to neuronal membranes (Saria et al., 1980). The $\mathrm{pH}$ of recording media was adjusted to 7.2 to 7.4 with $\mathrm{HCl}, \mathrm{KOH}$, or $\mathrm{NaOH}$ as needed. The osmolarity of solutions was maintained between 305 and 325 mOsm.

Peptides. Substance P (SP) and eledoisin-related peptide (ERP) were purchased from Sigma (St. Louis, MO) or Peninsula Laboratories (San Carlos, CA), weighed, and stored in a desiccator at $-25^{\circ} \mathrm{C}$ prior to putting them into solution. SP and ERP stock solutions (1 mM) were made by dissolving these peptides in $1 \mathrm{~mm}$ ammonium acetate/acetic acid buffer ( $\mathrm{pH} 4.6)$ with $0.1 \%$ bovine serum albumin (BSA) and $6 \mu \mathrm{M}$ dithiothreitol (Cleland's reagent). Aliquots $(100 \mu \mathrm{l})$ of stock solution were pipetted into BSA-coated plastic tubes and frozen. Thawed aliquots of peptide solutions were diluted serially each day with the buffered medium to be used in that experiment. Dithiothreitol $(6 \mu \mathbf{M})$ was added to peptide-containing and control mini perfusion solutions to prevent oxidation of the peptides (Otsuka and Konishi, 1976; Jordan and Owen, 1979). No dithiothreitol was added to recording 
medium or peptide solutions which contained $\mathrm{Co}^{2+}$ or $\mathrm{Mn}^{2+}$ since these cations appeared to oxidize the dithiothreitol, forming a brown precipitate. The peptide concentrations reported were the SP and ERP concentrations of the solutions ( $\mathrm{pH} 7.2$ to 7.4) used to fill the glass micropipettes.

Mini perfusion. Individual neurons were bathed locally with peptide-containing or control solutions during intracellular recording by pressure ejection of solutions from large tipped (2- to $10-\mu \mathrm{m}$-diameter) glass micropipettes (mini perfusion pipettes). Regulated pressure pulses were delivered through a tube fitted to the shank of the fluidfilled mini perfusion pipette. Manually controlled, electronically timed voltage pulses activated a three-way valve which opened the line to the regulated upstream air pressure (0.5 to $3.5 \mathrm{psi}$ ). Perfusion capability was tested prior to beginning an experiment by positioning the mini perfusion pipette tip against a small cell or bit of debris while ejecting fluid with brief pulses $(1 \mathrm{sec})$ and observing movements at the pipette tip. During intracellular recording, mini perfusion pipettes were placed in the oil layer covering the recording medium. Peptidecontaining and control pipettes were brought to within 5 to $15 \mu \mathrm{m}$ of the neuronal membrane and solutions were applied for 0.5 to $3 \mathrm{sec}$ with at least $2 \mathrm{~min}$ between applications. A membrane hyperpolarization without an associated membrane conductance change sometimes observed during mini perfusion of peptide-containing and control solutions was reduced or eliminated by decreasing the line pressure.

\section{Results}

$S P$ and ERP produced excitatory responses. SP and ERP evoked excitatory responses from spinal cord neu-
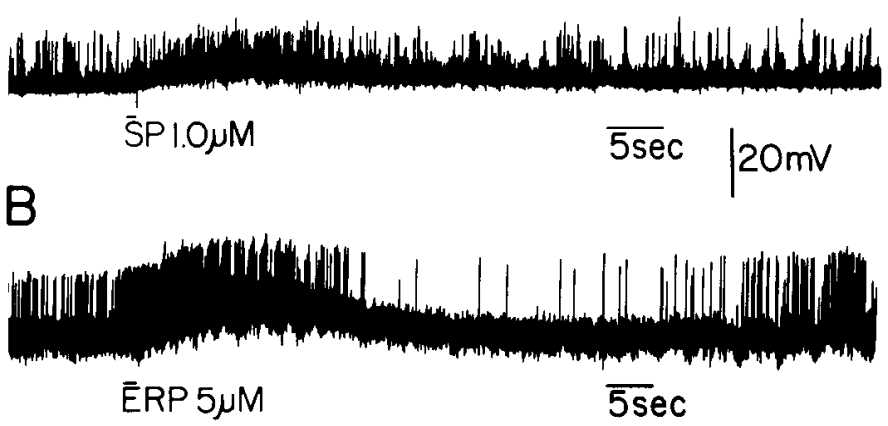

Figure 1. Substance $\mathrm{P}$ (SP) and eledoisin-related peptide (ERP) excited mouse spinal cord neurons in cell culture. $A, 1$ sec application of SP produced slow depolarization followed by rapid depolarization and bursts of action potentials lasting 1.5 min. The resting membrane potential $(R M P)$ was $-56 \mathrm{mV} . B$, ERP, applied for 2 sec also produced a slow depolarization and appeared to increase the number and frequency of action potentials and postsynaptic potentials. Excitation was followed by a period of depression before base line spontaneous activity was re-established. $R M P$ was $-50 \mathrm{mV}$. Recordings were made in PBS containing $1 \mathrm{mM} \mathrm{CaCl} 2$ and $1 \mathrm{mM} \mathrm{MgCl}_{2}$. The limited frequency response of the chart recorder truncated the action potentials.

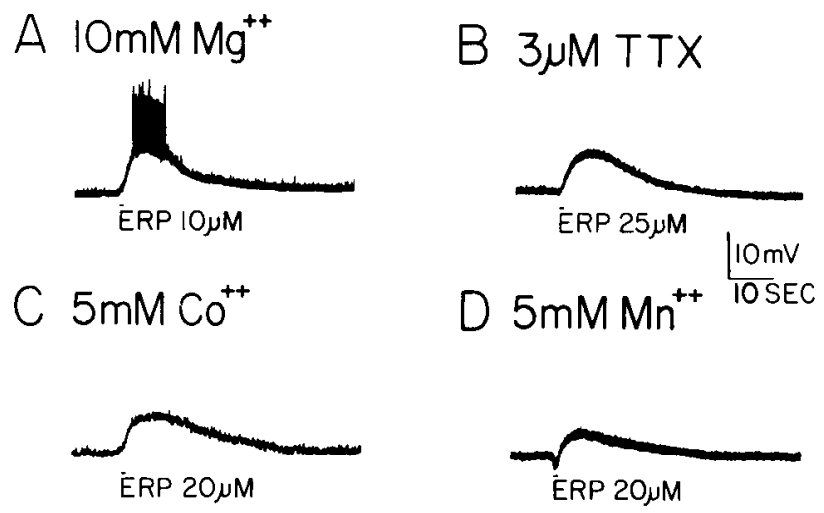

Figure 2. SP and ERP actions were postsynaptic. A, Reduction of spontaneous synaptic activity was observed from neurons in medium containing $10 \mathrm{mM} \mathrm{MgCl}_{2}$ which permitted ERP. and SP-evoked depolarizations to be clearly observed. The application of $10 \mathrm{mM}$ ERP for 1 sec produced a slow $(0.75-\mathrm{sec}$ latency), reversible depolarization. Occasionally, action potentials and postsynaptic potentials were observed during depolarization (SP in Fig. 5). $R M P$ was $-60 \mathrm{mV}$. $B$, Addition of tetrodotoxin (to $3 \mu \mathrm{M}$ ) blucked action potentials but did not abolish ERP or SP (see Figs. 3, 6, and 7) responses. $R M P$ was $-64 \mathrm{mV}$. Neurons bathed in medium containing calcium channel-blocking divalent cations, cobalt $(C)$ or manganese $(D)$, did not exhibit spontaneous synaptic activity, but ERP- and SPcvoked depolarization remained, suggesting that these were postsynaptic responses. $R M P$ s were -60 and $-58 \mathrm{mV}$, respectively. Recordings were made in Tris-HCl-buffered saline with constant osmolarity (see "Materials and Methods").

rons (19 of 32 cells), but not dorsal root ganglion neurons ( 0 of 8 cells), in primary dissociated cell culture bathed in PBS (Fig. 1). SP increased the action potential firing rate and increased both the frequency and amplitude of postsynaptic potentials (PSPs) (Fig. 1A). Action potentials and PSPs usually were observed superimposed on slowly developing, low amplitude, reversible depolarizations. Frequently $(52.6 \%)$, neurons responded to SP by bursting, occasionally with rapid, large amplitude depolarizations and bursts of action potentials which were superimposed on slower, low amplitude depolarizations. Response durations of 0.5 to $3 \mathrm{~min}$ were observed following a 1- to 3-sec application of 1 to $10 \mu \mathrm{M}$ SP or ERP. Excitation frequently was followed by depression (Fig. $1 B$ ) for a short interval before spontaneous activity was re-established.

SP and ERP had postsynaptic actions. The postsynaptic actions of SP and ERP were examined in medium containing $\mathrm{Mg}^{2+}(10 \mathrm{mM})$, TTX $(3 \mu \mathrm{M}), \mathrm{Co}^{2+}(5 \mathrm{mM})$, or $\mathrm{Mn}^{2+}(5 \mathrm{mM})$, all of which reduce or eliminate synaptic activity so that direct membrane actions could be recorded. SP and ERP depolarized 145 of 212 spinal cord neurons bathed in PBS or TBS containing either $10 \mathrm{~mm}$ $\mathrm{MgCl}_{2}$ or $3 \mu \mathrm{M}$ TTX. The application of SP and ERP to neurons bathed in TBS containing $10 \mathrm{mM} \mathrm{Mg} \mathrm{Mg}^{2+}$ evoked slow (0.75- to 1.5-sec latency), reversible depolarizing responses (Fig. 2A). Often there were action potentials on the peak of the peptide-induced depolarizations, especially if the neurons were depolarized by current injection before SP and ERP applications. While sodiumdependent action potentials were eliminated in recording medium containing $3 \mu \mathrm{M}$ TTX (thus eliminating synaptic 
activity), slow depolarizing responses to SP and ERP were unaffected (Fig. $2 B$ ). Thus, TTX was used in many experiments where the postsynaptic actions of SP and ERP were investigated. While it appeared that fewer neurons may have responded to ERP or SP in $\mathrm{Co}^{2+}$ containing $(48 \%, n=27)$ than in $\mathrm{Mn}^{2+}$-containing me$\operatorname{dium}(61 \%, n=13)$ or control medium $(68 \%, n=179)$, peptide responses were clearly obtained (Fig. $2 C, 5 \mathrm{~mm}$ $\mathrm{Co}^{2+}$; Fig. $2 D, 5 \mathrm{~mm} \mathrm{Mn}^{2+}$ ). Since SP and ERP responses were not eliminated when these channel blockers were added to the recording medium, it was concluded that the slow membrane depolarizations evoked by SP and ERP in TTX-, $\mathrm{Co}^{2+}$-, or $\mathrm{Mn}^{2+}$-containing medium were postsynaptic responses.

$S P$ responses were reduced by repetitive application. Repeatability of postsynaptic peptide responses was tested in 212 neurons at resting membrane potential in medium containing either $1 \mathrm{~mm} \mathrm{CaCl}_{2}$ (PBS or TBS; ERP, 55 of 78 cells; SP, 68 of 101 cells) or $5 \mathrm{mM} \mathrm{CaCl}_{2}$ (TBS; ERP, 4 of 7 cells; SP, 18 of 26 cells) with no apparent difference in the percentage of neurons that responded. Of the neurons which responded to $\mathrm{SP}$ or ERP and which received at least three consecutive applications from the same peptide-containing pipette, the percentage of responsive neurons decreased with repeated applications (see Table I). The SP responses were

TABLE 1

Decreased responsiveness to peptides with repeated applications

The table contains data from 34 neurons which received three successive applications of ERP and 56 neurons which received three successive applications of SP. Peptides were applied to neurons at resting membrane potential at 3 -min intervals. Neurons were bathed in PBS or TBS containing $10 \mathrm{~mm} \mathrm{Mg}^{2+}$ or $3 \mu \mathrm{M}$ TTX with 1 or $5 \mathrm{~mm}$ $\mathrm{CaCl}$. concentration. Since the percentage of neurons responding to $\mathrm{SP}$ or ERP in bathing medium containing 1 or $5 \mathrm{mM} \mathrm{Ca}^{2+}$ was similar, the data were combined. The peptide concentrations applied ranged from 1 to $20 \mu \mathrm{M}$.

\begin{tabular}{cccc}
\hline \multirow{2}{*}{ Peptide } & \multicolumn{3}{c}{ Number (Percent) of Neurons Responding } \\
\hline ERP & Trial 1 & Trial 2 & Trial 3 \\
SP & $34(100 \%)$ & $29(85 \%)$ & $28(82 \%)$ \\
\hline
\end{tabular}

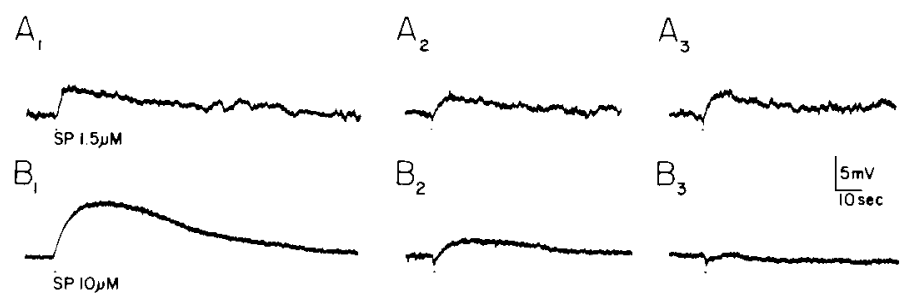

Figure 3. SP responses often were reduced by repeated application. $A, \mathrm{SP}$ repeatedly evoked responses from a small number of neurons without any decrement of response amplitude from the first $\left(A_{1}\right)$ to the second $\left(A_{2}\right)$ or third $\left(A_{3}\right)$ applications to the same neuron. $B$, Frequently, SP evoked a large initial response $\left(B_{t}\right)$ followed by smaller second $\left(B_{2}\right)$ and third $\left(B_{33}\right)$ responses from the same cell. Recordings were made in $(A) 1 \mathrm{mM} \mathrm{Ca}^{2+}$-containing or $(B) 5 \mathrm{mM} \mathrm{Ca}^{2+}$-containing TBS with $3 \mu \mathrm{M}$ TTX. $R M P$ s were $(A)-59$ and $(B)-54 \mathrm{mV}$. more diminished by repeated application than were the ERP responses.

With some neurons, SP response amplitude remained constant when SP was applied repetitively at 3-min intervals (Fig. $3 A$ ). In most cells, however, repetitive application of SP produced progressively smaller responses (Fig. $3 B$ ) or no response. Although it was not investigated systematically, it appeared that this phenomenon was more likely to occur when high SP concentrations (10 to $25 \mu \mathrm{M})$ were used. Stable responses were obtained from only $20 \%$ of the neurons which responded to SP (14\% of all neurons from which recordings were obtained). Data obtained from spinal cord neurons which consistently responded to repeated peptide applications (e.g., Fig. 3A) were used to examine dose responsivity and to investigate the ionic basis of SP responses. In addition, ERP was used in many experiments since consistent repeatable responses were more easily obtained with it than with SP.

$S P$ and ERP responses were dose dependent. Neuronal sensitivity to SP was variable so that small SP responses were evoked by high peptide concentrations (e.g., $25 \mu \mathbf{M}$ ) from some neurons, while large depolarizations were produced by lower concentrations (e.g., 500 nM) from other neurons. Thus, when SP responses of several cells were averaged for a particular peptide concentration, the mean $\mathrm{SP}$ response was $2.2 \mathrm{mV}$ at each concentration. However, if it was assumed that neurons which did not respond to a higher SP concentration did not respond to a lower concentration, pooling data from 14 neurons resulted in dose dependency, with average response amplitude increasing from 0.5 to $1.5 \mathrm{mV}$ as peptide concentration was increased from 1.7 to $10 \mu \mathrm{M}$. Moreover, more neurons responded to SP at progressively higher concentrations, resulting in an increase from 22 to $65 \%$ responding to SP as the peptide concentration was increased from 1.7 to $20 \mu \mathrm{M}$.

When it was possible to apply three or more different peptide concentrations to the same neuron $(n=6)$ with repeatable results, SP and ERP responses were dose dependent (Fig. 4). SP response amplitude was observed to saturate when higher peptide concentrations were used. The maximum rate of rise $\left(\dot{V}_{\max }\right)$ of SP and ERP responses was also dose dependent with $\dot{V}_{\text {max }}$ increasing as peptide concentration was increased from 0.5 to 10 $\mu \mathrm{M}$. At higher peptide concentrations, $\dot{V}_{\max }$ continued to increase despite amplitude saturation.

$S P$ and ERP decreased membrane potassium conductance. The amplitude of the voltage responses to constant current pulses (Fig. 5, $\triangle$ ) was increased during the slow depolarizing SP and ERP responses (Fig. 5, A), indicating that membrane conductance was decreased. When neurons were depolarized 10 to $15 \mathrm{mV}$ by direct current, voltage responses to constant current pulses decreased, suggesting that membrane conductance was increased with depolarization, not decreased as seen with SP and ERP. Since decreasing either chloride ion conductance $\left(g_{\mathrm{Cl}}\right)$ or potassium ion conductance $\left(g_{\mathrm{K}}\right)$ would produce depolarizing responses, intracellular recordings were made with $\mathrm{KCl}$-filled micropipettes which leak chloride ions into cells shifting the chloride equilibrium potential $\left(E_{\mathrm{cl}}\right)$ of these neurons from about -60 to $-20 \mathrm{mV}$ 


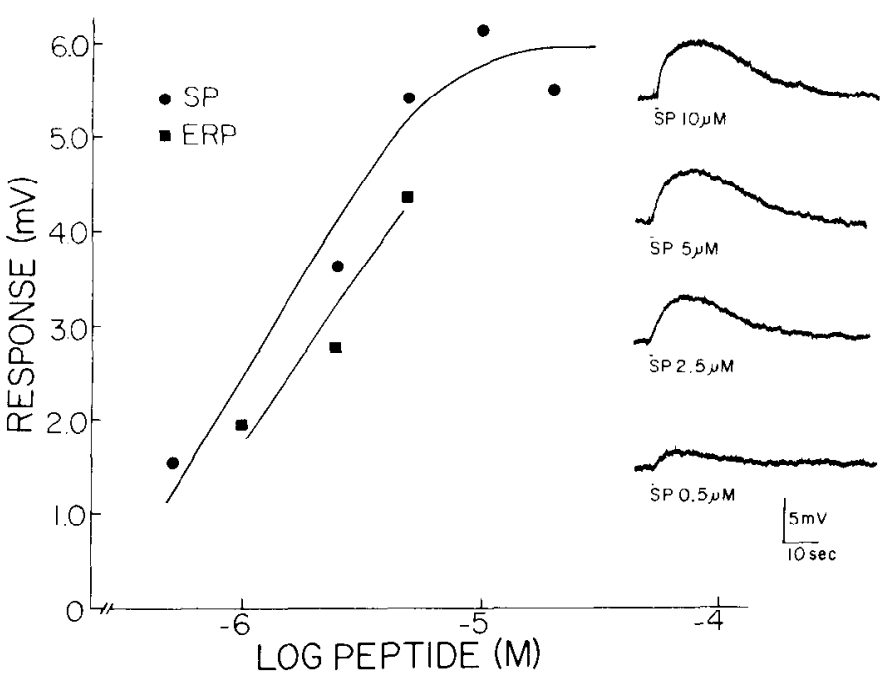

Figure 4. SP and ERP responses were dose dependent. SP (O) and ERP ( $\mathrm{G}$ ) responses were dose dependent for recordings from these two neurons as indicated by the graph, but sensitivity to the peptides differed among neurons (not shown). SP response amplitude saturated with higher doses of peptide. The maximum rate of rise ( $\dot{V}_{\text {max }}$ ) of SP and ERP responses increased as the peptide concentration was increased even when the SP response amplitude had saturated. The peptide concentrations plotted were the pipette concentrations. The raw data traces at the right were obtained during recording with a $4 \mathrm{M} \mathrm{KAc-}$ filled electrode from the same neuron using five mini perfusion pipettes. TBS recording medium contained $3 \mu \mathrm{M}$ TTX to eliminate action potentials. $R M P$ was $-62 \mathrm{mV}$.

(Barker and Ransom, 1978). However, SP and ERP responses (17 of 17 cells) were depolarizing, not hyperpolarizing, during $\mathrm{KCl}$ recording (Fig. 6 $A_{2}$ ), suggesting that SP did not decrease $g_{\mathrm{Cl}}$.

SP actions on $g_{K}$ were examined by blocking the conductance with intracellular or extracellular TEA ( $\Lambda \mathrm{rm}$ strong, 1969, 1971). In this experiment, each neuron ( $n=7$ ) was penetrated successfully with a pair of micropipettes. One micropipette contained $4 \mathrm{M} \mathrm{KAc}$ and was used to record SP responses. The second micropipette contained $4 \mathrm{M}$ TEA-Cl and was used for intracellular injection of TEA. A second SP response was evoked before TEA was injected by iontophoresis (Fig. 6Bl ) to insure that penetration with the second micropipette had not damaged the cell. Intracellular TEA increased membrane input resistance (by 1 to 12 megohms), produced membrane depolarization, and abolished the SP responses. Return of membrane potential to the original resting potential by injecting hyperpolarizing current through the recording micropipette did not restore the $\mathrm{SP}$ responses (Fig. $6 B_{2}$ ). SP responses were reduced in all 7 neurons and were eliminated in 6 of 7 neurons by intracellular injection of TEA, suggesting that SP decreased a TEA-sensitive $g_{K}$. Extracellular TEA (100 mM) did not eliminate SP responses (Fig. $6 C$ ), suggesting that $\mathrm{SP}$ decreased a membrane $g_{K}$ that was blocked more effectively by TEA on the inside of the membrane. Substitution of $100 \mathrm{~mm}$ TEA for $100 \mathrm{~mm}$ sodium in the recording medium significantly (independent $t$ test, $T=$
$4.09 ; d f=9 ; p<0.01$, two tailed) increased the mean input resistance $\left(R_{\mathrm{in}}=58.4\right.$ megohms $)$ compared to the mean resistance measured in normal medium $\left(R_{\mathrm{in}}=13.1\right.$ megohms), while resting membrane potentials were unchanged $(-55.0$ versus $-53.3 \mathrm{mV})$. Whether this increased $R_{\text {in }}$ was due to the addition of TEA and/or the deletion of sodium was not investigated.

$S P$ responses were not inverted by membrane hyperpolarization. If SP decreased a $g_{K}$, the amplitude of SP responses recorded at different membrane potentials $\left(V_{m}\right)$ should be a function of the potassium equilibrium potential $\left(E_{\mathrm{K}}\right)$. Thus, when $V_{m}$ equals $E_{\mathrm{K}}$, SP responses should be 0 and when $V_{m}$ is more negative than $E_{\mathrm{K}}, \mathrm{SP}$ responses should invert to become hyperpolarizing (Weight and Votava, 1970). During membrane polarization experiments, it was determined that SP responses were greater in amplitude when neurons $(n=34)$ were depolarized 10 to $15 \mathrm{mV}$ above resting membrane potential (Fig. 7, RMP, solid arrow) and smaller in amplitude when they were hyperpolarized 10 to $15 \mathrm{mV}$ below $R M P$. Therefore, the magnitude of $\mathrm{SP}$ responses was clearly dependent upon membrane potential and extrapolation of such polarization curves indicated reversal potentials should be more negative than resting membrane potential. Using a second intracellular micropipette to inject sufficient current to hyperpolarize neurons to potentials

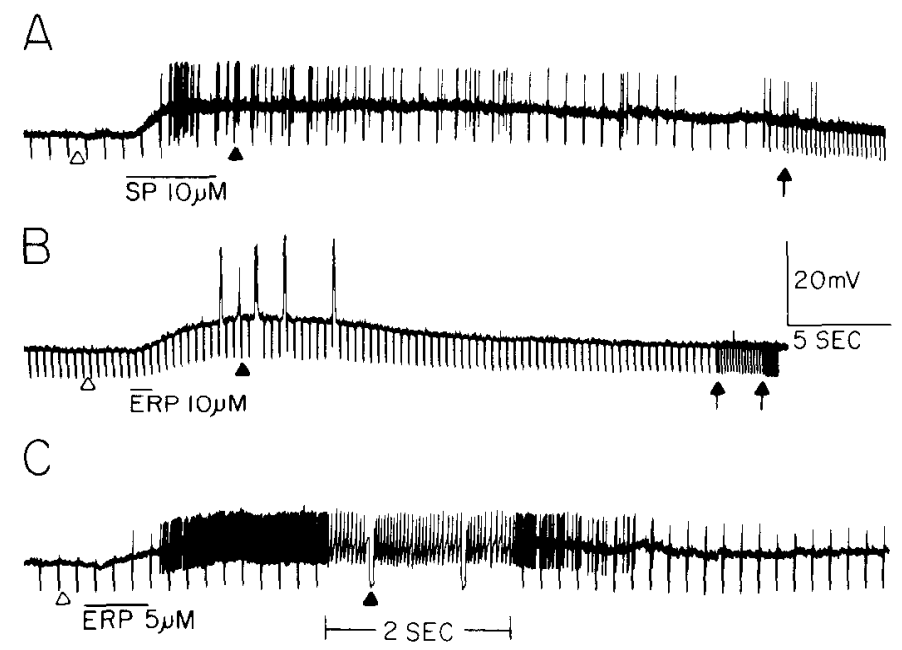

Figure 5. SP and ERP decreased membrane conductance during depolarizing responses. Brief ( 60 -msec), hyperpolarizing, constant current pulses were injected through the recording electrode using the bridge technique and the voltage responses were recorded. Following application of SP $(A)$ or ERP $(B$ and $C$ ), the neurons depolarized while the amplitude of the voltage responses to the constant current pulses increased (compare at $\Delta$ and $\Delta$ ), indicating that membrane conductance was decreased. The conductance decrease in $A$ was partially obscured hy hyperpolarizing afterpotentials of action potentials evoked by anodal break stimulation. Traces $B$ and $C(C$, increased chart speed for $2 \mathrm{sec}$ ) clearly show that the amplitude of the voltage pulses increased during depolarization and return to control upon repolarization. The chart speed was decreased in $A$ and $B$ (at arrows) to permit illustration of repolarization. Recordings were made in PBS containing $10 \mathrm{mM} \mathrm{Mg}^{2+}$. Recording electrodes contained $4 \mathrm{M} \mathrm{KAc}$ and $R M P$ s were $(A)-59$, $(B)-67$, and $(C)-50 \mathrm{mV}$. 


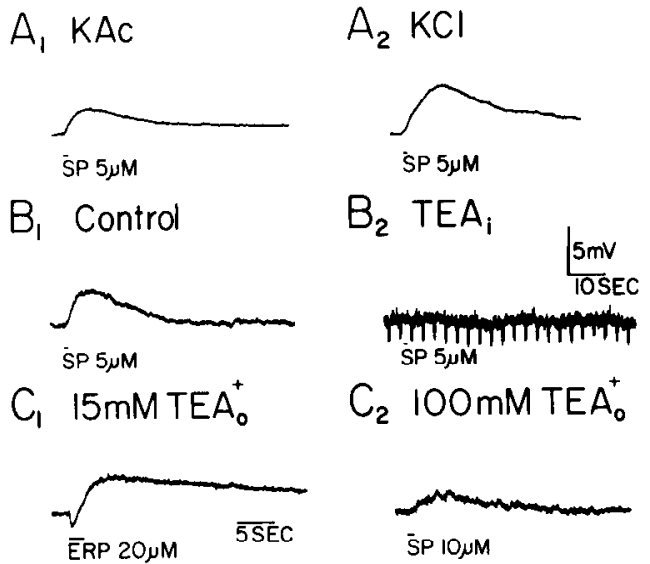

Figure 6. SP and ERP decreased potassium conductance. $A$, $\mathrm{SP}$ responses evoked during successive recordings from the same neuron with KAc-filled $\left(A_{1}\right)$ and $\mathrm{KCl}$-filled $\left(A_{2}\right)$ recording pipettes were depolarizing, suggesting that SP did not decrease chloride conductance. $R M P \mathrm{~s}$ were -66 and $-64 \mathrm{mV}$, respectively. $B$, Intracellular tetraethylammonium $\left(\mathrm{TEA}_{\mathrm{i}}\right)$, which blocks potassium conductance, reduced or eliminated SP responses. Neurons were penetrated initially with a KAc-filled recording pipette and a control SP response was evoked. Subsequently, the neuron was penetrated with a $4 \mathrm{M}$ TEA-Cl-filled micropipette and $\left(B_{l}\right)$ a second control SP response was evoked. TEA was injected into the soma by iontophoresis. Membrane resistance of this neuron was increased slightly (from 13.5 to 14.7 megohms), the cell was depolarized (from -66 to $-46 \mathrm{mV}$ ), and SP responses were eliminated. After TEA injection, SP did not depolarize this neuron $\left(B_{2}\right)$ nor did it decrease membrane conductance. $R M P$ was $-56 \mathrm{mV}$. $C$, Bath application of high TEA concentrations ( $T E A_{0} ; C_{2}, 100 \mathrm{~mm}$ ) may have reduced, hut did not eliminate, SP responses. Although lower TEA concentrations $\left(C_{l}, 15 \mathrm{~mm}\right)$ did not appear to alter SP or ERP responses, membrane input resistance was increased to $60 \mathrm{meg}$ ohms with substitution of $\mathrm{TEA}^{+}$for $\mathrm{Na}^{+}$in $C_{2}$. In some experiments $\left(C_{l}\right)$, the bathing medium also contained $5 \mathrm{~mm} 3$ aminopyridine which also blocks $g_{K} s$ (Yeh et al., 1976). Osmolarity of the $3 \mu \mathrm{M}$ TTX-containing TBS recording medium was maintained by reducing the sodium concentration. The traces in $A$ and $C$ were filtered $(-3 \mathrm{~dB}$ at $15 \mathrm{~Hz})$.

more negative than $30 \mathrm{mV}$ from resting membrane potential, no SP responses were recorded (Fig. 7, -106 and $-116 \mathrm{mV}$ ), and no clear reversal of SP response polarity was obtained $(n=4)$ at membrane potentials more negative than the predicted $E_{\mathrm{K}}$ (Fig. 7, open arrow). Thus, between -50 and $-120 \mathrm{mV}$, SP response amplitude was best described by a sigmoidal function of membrane potential. When the neurons were depolarized more than 10 or $15 \mathrm{mV}$, the amplitude of SP responses also decreased (Fig. 7). Since membrane conductance also increased when the membrane was depolarized, it was probable that membrane depolarization activated voltage-dependent conductances. The shape of the polarization curves indicated that SP responses did not vary as a linear function of membrane potential at hyperpolarized or depolarized potentials and that no true reversal potentials were obtained. Therefore, in further investigations, extrapolated reversal potentials $\left(R P_{\mathrm{e}} \mathrm{s}\right)$ were used (Fig. 7, open arrow).

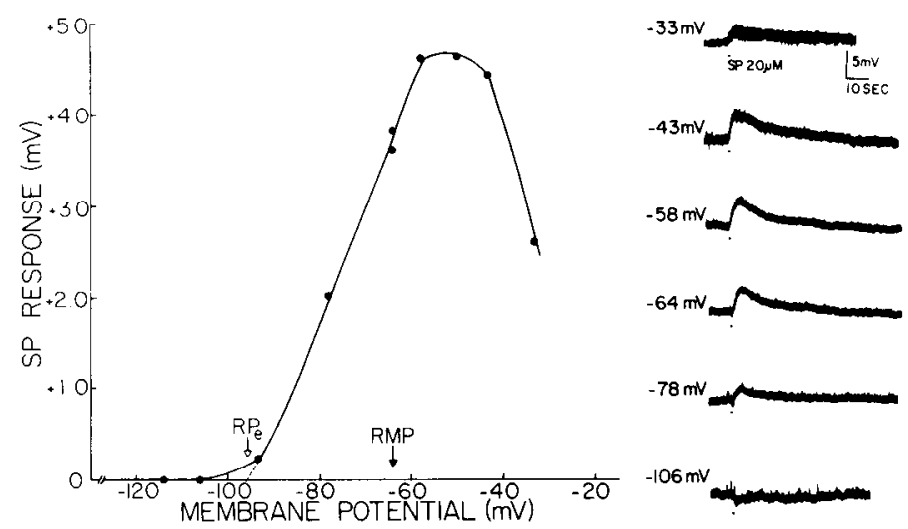

Figure 7. Clear reversal of SP response polarity was not obtained. SP and ERP response amplitude varied as a function of membrane potential, but the responses did not reverse polarity. SP response amplitude increased when the membrane was depolarized and decreased when it was hyperpolarized by one of two intracellular micropipettes. The response amplitude did not vary as a linear function of membrane potential at potentials less than $-50 \mathrm{mV}$ or greater than $-95 \mathrm{mV}$ in this neuron. While the activation of voltage-dependent conductances might reduce the voltage response recorded at potentials less than $-50 \mathrm{mV}$, it was not clear why no reversal of response polarity was seen. Even when this neuron was hyperpolarized to very negative potentials $(-106$ and $-114 \mathrm{mV})$, SP responses did not reverse polarity.

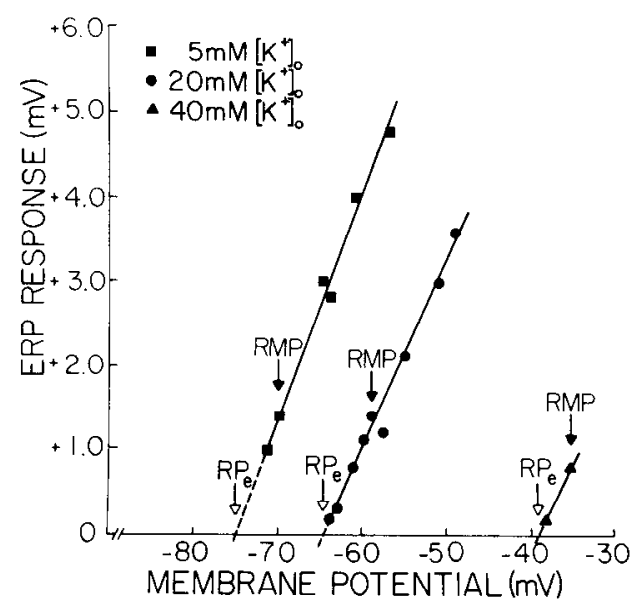

Figure 8. Extrapolated reversal potentials for SP and ERP responses were dependent upon extracellular potassium concentration $\left(\left[\mathrm{K}^{+}\right]_{0}\right)$. Polarization data from spinal cord neurons in medium containing $5(\square), 20(O)$, and $40 \mathrm{mM} \mathrm{K}^{+}(\Delta)$ showed that the extrapolated reversal potentials ( $R P_{e}$ see dashed lines) for ERP responses (SP data included in Fig. 9) varied as a function of $\left[\mathrm{K}^{+}\right]_{\ldots}$. Responses were extrapolated to 0 at -76.5 $\mathrm{mV}$ in $5 \mathrm{mM} \mathrm{K} \mathrm{K}^{+}(R M P,-70 \mathrm{mV}),-64.5 \mathrm{mV}$ in $20 \mathrm{mM} \mathrm{K}^{+}$ $(R M P,-59 \mathrm{mV})$, and $-39 \mathrm{mV}$ in $40 \mathrm{mM} \mathrm{K}^{+}(R M P,-35 \mathrm{mV})$ for these three neurons, indicating that $R P_{e}$ was more negative than $R M P$ for each neuron and that $R P_{e}$ and $R M P$ varied as $\left[\mathrm{K}^{+}\right]_{\text {o }}$ was altered.

$S P$ and $E R P R P_{e} s$ varied with $\left[K^{+}\right]_{o}$. The dependency of SP responses on $E_{\mathrm{K}}$ was studied by evoking peptide responses in experiments where the extracellular potassium concentration $\left(\left[\mathrm{K}^{+}\right]_{0}\right)$ was varied. Membrane poten- 
tial was changed by passing steady current through one of two intracellular micropipettes and SP and ERP responses were measured at different membrane potentials in $\left[\mathrm{K}^{+}\right]_{\mathrm{o}}$ concentrations of 5,20 , and $40 \mathrm{~mm}$ (Fig. 8). The reversal potentials of SP and ERP responses were extrapolated (Fig. 8, dashed lines) for each neuron. The $R P_{e}$ values for ERP responses in 5,20 , and $40 \mathrm{mM}\left[\mathrm{K}^{+}\right]_{\mathrm{o}}$ were $-76.5,-64$, and $-39 \mathrm{mV}$, respectively, indicating that increasing $\left[\mathrm{K}^{+}\right]_{\mathrm{o}}$ shifted $R P_{e}$ to more depolarized potentials. Resting membrane potentials ( $R M P \mathrm{~s})$ also changed as $\left[\mathrm{K}^{+}\right]_{0}$ was varied (Fig. 8, solid arrows) as would be expected if the neuronal membrane were permeable to potassium. $R P_{e} \mathrm{~s}$ (open arrows) were always more negative than $R M P$ s from the same neurons, suggesting that SP and ERP responses were dependent upon $E_{\mathrm{K}}$.

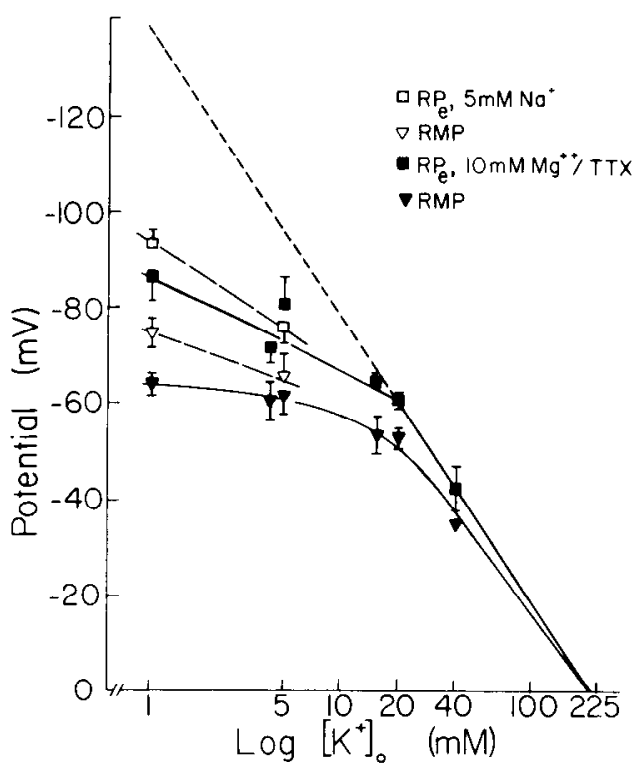

Figure 9. Extrapolated reversal potentials ( $R P_{\mathrm{es}}$ ) of SP and ERP responses did not vary linearly with the $\log \left[\mathrm{K}^{+}\right]_{0}$ in normal ( $\nabla$ and $\square$ ) or reduced sodium medium ( $\nabla$ and $\square)$. The mean $R P_{e}$ of SP and ERP responses was calculated and plotted (C) as a function of the $\log _{10}$ of $\left[\mathrm{K}^{+}\right]_{\mathrm{o}}$. It was observed that the $K P_{e}$ and mean $R M P$ changed as predicted by the Nernst equation for potassium (dashed line; slope, $-61 \mathrm{mV} / 10$-fold change of $\left.\left[\mathrm{K}^{+}\right]_{\mathrm{o}}\right)$ in 20 and $40 \mathrm{mM}\left[\mathrm{K}^{+}\right]_{\mathrm{o}}$ concentrations but that the $R P_{e}$ and $R M P$ were more depolarized than predicted in $\left[\mathrm{K}^{+}\right]_{\mathrm{o}}$ concentrations of 1 and $5 \mathrm{~mm}$. Each point represents 2 to 10 cells. Recordings were made using the two-electrode current clamp method from neurons in $10 \mathrm{mM} \mathrm{Mg}^{2+}$-containing PBS or $3 \mu \mathrm{M}$ TTX-containing TBS. Extrapolated reversal potentials were not altered significantly by the reduction of extracellular sodium (compare $\square$ and $\square$ ) remaining more depolarized than predicted by the Nernst potential for potassium. Low sodium data were obtained from 6 neurons bathed in TBS with 140 mM choline substituted for all but $5 \mathrm{mM} \mathrm{Na}^{+}$in either 1 or 5 mM $\left[\mathrm{K}^{+}\right]_{\mathrm{o}}$. Resting membrane potential $(\nabla)$ was increased significantly (Student's $t$ test, $T=2.60 ; d f=11 ; p<0.05$, two tailed) by the reduction from normal extracellular sodium $(\nabla)$ for $1 \mathrm{mM}\left[\mathrm{K}^{+}\right]_{\mathrm{o}}$ but not for $5 \mathrm{mM}\left[\mathrm{K}^{+}\right]_{\mathrm{o}}$. Resting membrane potentials in reduced $\mathrm{Na}^{+}$medium remained less negative than would be expected if they were determined only by potassium. The bars show the SE of the mean. The $\mathrm{CaCl}_{2}$ concentration was increased (from 1 to $5 \mathrm{~mm}$ ) in low sodium TBS to increase recording stability.
$R P_{e} s$ were not predicted by the Nernst equation in low $\left[\mathrm{K}^{+}\right]_{o}$ concentrations. The dependency of SP and ERP responses on $\left[\mathrm{K}^{+}\right]_{\mathrm{o}}$ was examined thoroughly using $R P_{e} \mathrm{~s}$ obtained in medium containing $1,5,10,15,20$, or $40 \mathrm{~mm}$ $\mathrm{K}^{+} . R P_{e s}$ plotted as a function of the $\log _{10}$ of $\left[\mathrm{K}^{+}\right]_{\mathrm{o}}$ (Fig. $9, \square)$ were related linearly to $\left[\mathrm{K}^{+}\right]_{\mathrm{o}}$ in high $\left[\mathrm{K}^{+}\right]_{\mathrm{o}}$ concentrations with a slope of $-61 \mathrm{mV}\left(35^{\circ} \mathrm{C}\right)$ for a 10 -fold change of $\left[\mathrm{K}^{+}\right]_{\mathrm{o}}$ as predicted by the Nernst equation (Fig. 9 , dashed line) for potassium ions. However, $R P_{e}$ for $S P$ and ERP responses were more depolarized than predicted for $\left[\mathrm{K}^{+}\right]_{\text {o }}$ concentrations of 1 and $5.0 \mathrm{~mm}$. Thus, the finding that $R P_{s}$ in low $\left[\mathrm{K}^{+}\right]_{\mathrm{o}}$ concentrations were not predicted by the Nernst equation for potassium may have indicated that SP decreased another ionic conductance, namely $g_{\mathrm{Na}}$, in addition to $g_{\mathrm{K}}$ or that the $g_{\mathrm{K}} \mathrm{de}$ creased by SP was small in magnitude at hyperpolarized potentials (i.e., a voltage-dependent $g_{K}$ ).

If $\mathrm{SP}$ decreased $g_{\mathrm{Na}}$ in addition to $g_{\mathrm{K}}, R P_{e} \mathrm{~S}$ would be more depolarized than predicted by the Nernst equation for potassium since the response reversal potential should be between $E_{\mathrm{K}}$ and $E_{\mathrm{Na}}$. We investigated the sodium dependence of $R P_{e}$ by repeating membrane polarization (two-electrode method) experiments in medium with 140 to $145 \mathrm{~mm}$ choline chloride substituted for all but $5 \mathrm{mM}$ $\mathrm{NaCl}$ (Fig. 9, $\nabla$ and $\square$ ). The $R P_{e} \mathrm{~s}$ of $\mathrm{SP}$ responses obtained in low $\mathrm{Na}^{+}(n=6)$ were not significantly different from those measured in normal sodium recording medium, suggesting that $\mathrm{SP}$ did not reduce $g_{\mathrm{Na}}$ in addition to $g_{\mathrm{K}}$ (Fig. 9; $\square$ ). The $R M P$ s of neurons in solutions containing $5 \mathrm{mM} \mathrm{Na}{ }^{+}, 1 \mathrm{mM} \mathrm{K} \mathrm{K}^{+}$were significantly $(p<$ $0.05)$ more negative compared to $R M P \mathrm{~s}$ from neurons in normal sodium medium $\left(145 \mathrm{mM} \mathrm{Na}{ }^{+}\right.$and $\left.1 \mathrm{mM} \mathrm{K}^{+}\right)(\nabla$ versus $\nabla$ ), indicating a sodium dependence for RMP.

\section{Discussion}

SP depolarized spinal cord neurons by reducing a membrane potassium conductance. The postsynaptic excitatory action of SP and ERP was due to a decrease of a membrane $g_{K}$. These data are consistent with findings in cat dorsal horn neurons (Krnjević, 1977), guinea pig myenteric neurons (Katayama and North, 1978; Katayama et al. 1979; Grafe et al., 1979), and cultured rat spinal cord neurons (Hösli et al., 1981). However, in other studies of cat dorsal horn neurons (Zieglgänsberger and Tulloch, 1979; Sastry, 1979) and frog and rat motor neurons (Nicoll, 1978; Otsuka and Konishi, 1977), membrane conductance either remained the same or increased. Since we applied peptides from relatively large tipped micropipettes, thus bathing a larger neuronal surface area than possible by the iontophoretic technique, it was more likely that small decreases in membrane conductance were detected. In frog spinal cord neurons, Nicoll (1978) reported slightly increased conductance following SP perfusion. Otsuka and Konishi (1977) obtained a similar increase in membrane conductance of rat motor neurons. Although this increase in membrane conductance may reflect a difference among preparations, an alternative explanation is that the membrane depolarization may have activated voltage-dependent conductances which masked any coincident SP-induced decrease in conductance in these neurons. Rapidly desensitizing SP responses associated with an increase in mem- 
brane conductance described in mouse spinal cord neurons in cell culture were not observed in our experiments (Vincent and Barker, 1979).

$S P$ and ERP reduced a voltage-dependent $g_{K}$. The hypothesis that $\mathrm{SP}$ decreased a voltage-dependent $g_{K}$ was supported by the finding that SP and ERP responses were not obtained at large negative membrane potentials. Moreover, the responses did not clearly reverse polarity at membrane potentials that were more negative than the extrapolated reversal potential. Thus, the amplitude of SP and ERP responses obtained from neurons polarized to different membrane potentials varied as a sigmoidal, not linear, function of potential between -50 and $-120 \mathrm{mV}$. Finally, investigation of the hypothesis that SP also decreased a $g_{\mathrm{Na}}$ indicated that the nonlinear dependence of $R P_{e}$ s on $\left[\mathrm{K}^{+}\right]_{\mathrm{o}}$ at large negative potentials was unaltered by reduction of $\left[\mathrm{Na}^{+}\right]_{0}$. The possibility remains that reversal of $\mathrm{SP}$ responses might be observed at large negative membrane potentials (even though SP reduced a voltage-dependent $g_{K}$ ) if $g_{K}$ was sufficiently large at some potentials more negative than $E_{\mathrm{K}}$. However, if leak conductance $\left(g_{\mathrm{L}}\right)$ contributed a greater percentage of the total membrane conductance at these potentials than the $g_{K}$ reduced by SP (the affected $g_{K}$ being present but small), responses of reversed polarity would not be seen due to the shunting effect of the larger $g_{\mathrm{L}}$. Alternatively, if SP closes channels that normally permit outward potassium current but have low conductance for inward potassium current (channel rectification), SP responses might not be observed at potentials more negative than $E_{\mathrm{K}}$ since there would be little inward potassium current to be blocked.

Which voltage-dependent $g_{K}$ was reduced? Substance $\mathrm{P}$ actions are not unique since a number of putative neurotransmitters produce slow responses attributed to increasing or decreasing potassium conductances (see Kehoe and Marty, 1980, for review). In particular, acetylcholine evokes slow excitatory responses in central (Krnjević et al., 1971; Dodd et al., 1981; Nowak and Macdonald, 1981b) and peripheral (Weight and Votava, 1970; Brown and Adams, 1980; Brown and Constanti, 1980; Freschi and Shain, 1980) neurons due to a decrease of potassium conductance. Muscarinic cholinergic action on frog sympathetic ganglion neurons (Brown and Adams, 1980) and mammalian hippocampal (Adams et al., 1981) and spinal cord (Nowak and Macdonald, 1981b, 1982) neurons was shown to be due to a decrease of a voltage-dependent slow potassium current. This muscarine-sensitive potassium conductance $\left(g_{\mathrm{Km}}\right)$ was present at resting membrane potential and was activated by depolarization in these neurons, whereas the voltagedependent potassium conductance responsible for repolarizing cells during action potentials (Hodgkin and Huxley, 1952) ( $\left.g_{\mathrm{Kv}}\right)$ was not activated at potentials more negative than $-20 \mathrm{mV}$. In addition, $g_{K_{m}}$ was not blocked by extracellular TEA, while $g_{\mathrm{Kv}}$ was unaltered by muscarine but abolished by TEA, thereby establishing $g_{\mathrm{Kv}}$ and $g_{K m}$ as separate conductances. It was reported recently that luteinizing hormone-releasing hormone decreased $g_{\mathrm{Km}}$ in frog sympathetic ganglion neurons (Adams and Brown, 1980; Brown et al., 1981) and that another hormone, angiotensin II, mimicked muscarinic agonist responses on rat sympathetic ganglion neurons (Brown et al., 1980). Thus, it is tempting to speculate that SP might also decrease $g_{\mathrm{Km}}$ which has been demonstrated recently in cultured mouse spinal cord neurons (Nowak and Macdonald, 1982). Moreover, it is unlikely that SP and ERP reduced $g_{K v}$ because peptide responses were present at resting membrane potential where $g_{K v}$ is not yet activated and SP responses were still present in neurons in TEA-containing bathing medium.

\section{References}

Adams, D. J., and P. W. Gage (1979) Ionic currents in response to membrane depolarization in an Aplysia neurone. J. Physiol. (Lond) 289: 115-141.

Adams, P. R., and D. A. Brown (1980) Luteinizing hormonereleasing factor and muscarinic agonists act on the same voltage-sensitive $\mathrm{K}^{+}$-current in bullfrog sympathetic neurones. Br. J. Pharmacol. 68: 353-355.

Adams, P. R., D. A. Brown, and J. V. Halliwell (1981) Cholinergic regulation of $\mathbf{M}$-current in hippocampal pyramidal cells. J. Physiol. (Lond) 317: 29-30.

Armstrong, C. M. (1969) Inactivation of the potassium conductance and related phenomena caused by quaternary ammonium ion injection in squid axons. J. Gen. Physiol. 54: 553-575.

Armstrong, C. M. (1971) Interaction of tetraethylammonium ion derivatives with potassium channels of giant axons. J. Gen. Physiol. 58: 413-437.

Baker, P. F., H. Meves, and E. B. Ridgeway (1973) Effects of manganese and other agents on the calcium uptake that follows depolarization of squid axons. J. Physiol. (Lond.) 231: 511-526.

Barber, R. P., J. E. Vaughn, J. R. Slemmon, P. M. Salvaterra, E. Roberts, and S. E. Leeman (1979) The origin, distribution and synaptic relationships of substance $\mathrm{P}$ axons in rat spinal cord. J. Comp. Neurol. 184: 331-352.

Barker, J. L., and B. R. Ransom (1978) Amino acid pharmacology of mammalian central neurones grown in tissue culture. J. Physiol. (Lond.) 280: 331-354.

Brown, D. A., and P. R. Adams (1980) Muscarinic suppression of a novel voltage-sensitive $\mathrm{K}^{+}$current in a vertebrate neurone. Nature 283: 673-676.

Brown, D. A., and A. Constanti (1980) Intracellular observations on the effects of muscarinic agonists on rat sympathetic neurones. Br. J. Pharmacol. 70: 593-608.

Brown, D. A., A. Constanti, and S. Marsh (1980) Angiotensin mimics the action of muscarinic agonists on rat sympathetic neurones. Brain Res. 193: 614-619.

Brown, D. A., A. Constanti, and P. R. Adams (1981) Slow cholinergic and peptidergic transmission in sympathetic ganglia. Fed. Proc. 40: 2625-2630.

Chan-Palay, V., and S. L. Palay (1977) Ultrastructural identification of substance $P$ cells and their processes in rat sensory ganglia and their terminals in the spinal cord by immunocytochemistry. Proc. Natl. Acad. Sci. U. S. A. 74: 4050-4054.

Cuello, A. C., M. del Fiacco, and G. Paxinos (1978) The central and peripheral ends of the substance P-containing sensory neurones in the rat trigeminal system. Brain Res. 157: 499-507.

Dodd, J., R. Dingledine, and J. S. Kelly (1981) The excitatory action of acetylcholine on hippocampal neurones of the guinea pig and rat maintained in vitro. Brain Res. 207: 109-127.

Uun, N. J., and A. G. Karczmar (1979) Actions of substance P 
on sympathetic neurons. Neuropharmacology 18: 215-218.

Freshi, J. E., and W. G. Shain (1980) Slow muscarinic depolarization in neurons of dissociated rat superior cervical ganglion can be evoked by iontophoresis of acetylcholine. Brain Res. 185: 429-434.

Godfrey, E., P. Nelson, B. Schrier, A. Breuer, and B. Ransom (1975) Neurons from fetal rat brain in a new cell culture system: Multidisciplinary analysis. Brain Res. 90: 1-21.

Grafe, P., C. J. Mayer, and J. D. Wood (1979) Evidence that substance $P$ does not mediate slow synaptic excitation within the myenteric plexus. Nature 279: 720-721.

Hayes, A. G., and M. B. Tyers (1980) Effects of capsaicin on nociceptive heat, pressure and chemical thresholds and on substance $P$ levels in the rat. Brain Res. 189: 561-564.

Henry, J. L. (1976a) Effects of substance $P$ on functionally identified units in cat spinal cord. Brain Res. 114: 439-452.

Henry, J. L. (1976b) Substance P and pain: An updating. Trends Neurosci. 3: 95-97.

Henry, J. L., B. J. Sessle, G. E. Lucier, and J. W. Hu (1980) Effects of substance $\mathrm{P}$ on nociceptive and non-nociceptive trigeminal brain stem neurons. Pain 8: 33-45.

Heyer, E. J., and R. L. Macdonald (1982) Calcium- and sodiumdependent action potentials in mammalian spinal cord and dorsal root ganglion neurons in dissociated cell culture. J. Neurophysiol. 47: 641-655.

Hodgkin, A. L., and A. F. Huxley (1952) A quantitative description of membrane current and its application to conduction and excitation in nerve. J. Physiol. (Lond.) 117: 500-544.

Hükfelt, T., J. O. Kellerth, G. Nilsson, and B. Pernow (1975) Experimental immunohistochemical studies on the localization and distribution of substance $P$ in cat primary sensory neurons. Brain Res. 100: 235-252.

Hökfelt, T., A. Ljundahl, L. Terenius, R. Elde, and G. Nilsson (1977) Immunohistochemical analysis of peptide pathways possibly related to pain and analgesia: Enkephalin and substance P. Proc. Natl. Acad. Sci. U. S. A. 74: 3081-3085.

Hökfelt, 'T., A. Ljundahl, H. Steinbusch, A. Verhofstad, G. Nilsson, E. Brodin, B. Pernow, and M. Goldstein (1978) Immunohistochemical evidence of substance P-like immunoreactivity in some 5-hydroxytryptamine-containing neurons in the rat central nervous system. Neuroscience 3 : 517-538.

Hösli, L., E. Hösli, Ch. Zehntner, and H. Landolt (1981) Effects of substance $\mathrm{P}$ on neurones and glial cells in cultured rat spinal cord. Neurosci. Lett. 24: 165-168.

Jessell, T. M., A. Tsunoo, I. Kanazawa, and M. Otsuka (1979) Substance P: Depletion in the dorsal horn of rat spinal cord after section of the periferal processes of primary sensory neurons. Brain Res. 168: 247-259.

Jordan, C. C., and D. G. Owen (1979) Dithiothreitol potentiates the depolarizing action of substance $P$ in the frog spinal cord. Proc. Br. Pharmacol. Soc. 23: 285P.

Katayama, Y., and R. A. North (1978) Does substance P mediate slow synaptic excitation within the myenteric plexus? Nature 274: 387-388.

Katayama, Y., R. A. North, and J. T. Williams (1979) The action of substance $P$ on neurons of the myenteric plexus of the guinea-pig small intestine. Proc. R. Soc. Lond. (Biol.) 206: 191-208.

Katz, B., and R. Miledi (1967) Ionic requirements of synaptic transmitter release. Nature 215: 615 .

Kehoe, J -S., and A. Marty (1980) Certain slow synaptic responses: Their properties and possible underlying mechanisms. Annu. Rev. Biophys. Bioeng. 9: 437-465.

Konishi, S., and M. Otsuka (1974a) The effects of substance P and other peptides on spinal neurons of the frog. Brain Res. 65: $397-410$.
Konishi, S., and M. Otsuka (1974b) Excitatory action of hypothalamic substance $\mathrm{P}$ on spinal motoneurones of newborn rats. Nature 252: 734-735.

Krnjević, K. (1977) Effects of substance P on central neurons in cats. In Substance P, U. S. von Euler and B. Pernow, ed., pp. 217-230, Raven Press, New York.

Krnjević, K., R. Pumain, and L. Renaud (1971) The mechanism of excitation by acetylcholine in the cerebral cortex. J. Physiol. (Lond.) 215: 247-268.

Lembeck, F. (1953) Zur frage der zentralen Ubertragung afferenter Impulse III. Das Vorkommen und die Bedeutung der Substance $\mathbf{P}$ in cen dorsal Würzeln des Rüchenmarks. Arch. Exp. Pathol Pharmakol. 219: 197-213.

Ljundahl, A., T. Hökfelt, and G. Nilsson (1978) Distribution of substance P-like immunoreactivity in the central nervous system of the rat. I. Cell bodies and nerve terminals. Neuroscience 3: $861-880$.

Macdonald, R. L., and L. M. Nowak (1981) Substance P and somatostatin actions on spinal cord neurons in primary dissociated cell culture. In Neurosecretion and Brain Peptides, J. B. Martin, S. Reichlin, and K. L. Bick, ed., pp. 159-174, Raven Press, New York.

Narahashi, T., J. W. Moore, and W. R. Scott (1964) 'Tetrodotoxin in blockage of sodium conductance increase in lobster giant axons. J. Gen. Physiol. 47: 965-974.

Nicoll, R. A. (1978) The action of thyrotropin-releasing hormone, substance $\mathbf{P}$ and related peptides on frog spinal motoneurons. J. Pharmacol. Exp. Ther. 207: 817-824.

Nowak, L. M., and R. L. Macdonald (1981a) Substance P decreases a potassium conductance of spinal cord neurons in cell culture. Brain Res. 214: 416-423.

Nowak, L. M., and R. L. Macdonald (1981b) $d l$-Muscarine decreases a potassium conductance to depolarize mammalian spinal cord neurons in cell culture. Soc. Neurosci. Abstr. 7: 725.

Nowak, L. M., and R. L. Macdonald (1982) Muscarine (MUS) decreased a voltage-dependent potassium current in mouse spinal cord neurons in cell culture. Biophys. J. 37: 310a.

Otsuka, M., and S. Konishi (1976) Release of substance P-like immunoreactivity from isolated spinal cord of newborn rat. Nature 264: 83-84.

Otsuka, M., and S. Konishi (1977) Electrophysiological and neurochemical evidence for substance $P$ as a transmitter of primary sensory neurons. In Substance $P$, U. S, von Euler, and B. Pernow, ed., pp. 207-214, Raven Press, New York.

Otsuka, M., S. Konishi, and T. Takahashi (1975) Hypothalamic substance $\mathrm{P}$ as a candidate for transmitter of primary afferent neurons. Fed. Proc. 34: 1922-1928.

Peacock, J., P. Nelson, and M. Goldstone (1973) Electrophysiologic study of cultured neurons dissociated from spinal cords and dorsal root ganglia of fetal mice. Dev. Biol. 30: 137-152.

Randić, M., and V. Miletić (1977) Effects of substance $P$ in cat dorsal horn neurones activated by noxious stimuli. Brain Res. 128: 164-169.

Ransom, B., and R. Holz (1977) Ionic determinants of excitability in cultured mouse dorsal root ganglion and spinal cord cells. Brain Res. 136: 445-453.

Ransom, B. R., E. Neale, M. Hjenkart, P. N. Bullock, and P. G. Nelson (1977) Mouse spinal cord in cell culture. I. Morphology and intrinsic neuronal electrophysiologic properties. J. Neurophysiol. 40: 1132-1150.

Saria, A, N. Mayer, F. Lembeck, and M. Pabst (1980) Regional distribution and biochemical properties of ${ }^{125}{ }^{1}-\mathrm{Tyr}^{\gamma}$-substance $\mathrm{P}$ binding sites in synaptic vesicles. Naunyn Schmiedebergs Arch. Pharmacol. 311: 151-157.

Sastry, B. R. (1979) Substance P effects on spinal nociceptive neurones. Life Sci. 24: 2169-2178. 
Takahashi, T., and M. Otsuka (1975) Regional distribution of substance $P$ in the spinal cord and nerve roots of the cat and the effect of dorsal root section. Brain Res. 87: 1-11.

Vacca, L. L., S. J. Abrahams, and N. E. Naftchi (1980) A modified peroxidase-antiperoxidase procedure for improved localization of tissue antigens: Localization of substance $P$ in rat spinal cord. J. Histochem. Cytochem. 28: 297-307.

Vincent, J. -D., and J. L. Barker (1979) Substance P: Evidence for diverse roles in neuronal function from cultured mouse spinal neurons. Science 205: 1409-1411.
Weight, F. F., and J. Votava (1970) Slow synaptic excitation in sympathetic ganglion cells: Evidence for synaptic inactivation of potassium conductance. Science 170: 755-758.

Yeh, J. Z., G. S. Oxford, and T. Narahashi (1976) Interactions of aminopyridines with potassium channels of squid axon membranes. Biophys. J. 16: 77-81.

Zieglgänsberger, W., and I. F. Tulloch (1979) Effects of substance $P$ on neurones in the dorsal horn of the spinal cord of the cat. Brain Res. 166: 273-282. 